\title{
Severe hypokalaemia from kaolin and morphine abuse
}

\author{
Bruce Kirkham, Richard Cowell and John Rees
}

Lewisham Hospital, Lewisham High Street, London SE13, UK

\begin{abstract}
Summary: A 34 year old man, registered disabled as a result of muscle weakness, was admitted to hospital because of increasing weakness. He had profound hypokalaemia and admitted to taking up to $1400 \mathrm{ml}$ of kaolin and morphine mixture daily. After considerable potassium replacement muscle power recovered completely. The hypokalaemia is likely to have been caused by the combination of liquorice extract and sodium bicarbonate in kaolin and morphine.
\end{abstract}

\section{Introduction}

Hypokalaemia has a number of causes. We describe a case precipitated by the ingestion of very large quantities of kaolin and morphine mixture. The case illustrates the importance of a full drug history including preparations not obtained on prescription.

\section{Case report}

A 34 year old man was admitted to hospital because of severe muscle weakness. He had been admitted 14 and 10 months previously with paraesthesia and weakness. Investigations had shown a mild sensory axonal polyneuropathy on the first occasion and hypokalaemia $(2.1 \mathrm{mmol} / \mathrm{l})$ on both occasions. Clinical examination of sensory function after the first admission was normal. He had discharged himself against advice, taking oral potassium supplements, although he had soon stopped taking these. He had taken no prescribed medication for at least 2 weeks prior to his admission.

He was registered disabled and had been able to walk only with the aid of two sticks for 2 weeks. At the time of admission he could do little more than lift his arms. Lower limb power was $2 / 5$ with normal reflexes. Sensation was normal. His blood pressure was 130/ $80 \mathrm{~mm} \mathrm{Hg}$. The electrocardiogram showed unifocal ventricular ectopics with periods of bigeminy.

Investigations showed a hypokalaemic, hypochloraemic alkalosis; sodium $144 \mathrm{mmol} / 1$, potassium $1.2 \mathrm{mmol} / \mathrm{l}$, chloride $83 \mathrm{mmol} / \mathrm{l}$, bicarbonate $40 \mathrm{mmol} / \mathrm{l}$. Calcium and magnesium were normal as was liver function. Serum creatinine was normal, $80 \mu \mathrm{mol} / 1$. His metabolic alkalosis was partially compensated by

Correspondence: J. Rees, M.D., M.R.C.P., Clinical Classroom, Guy's Hospital, London SE1 9RT, UK

Accepted: 18 February 1987 respiratory depression; $\mathrm{pH} 7.46, \mathrm{PO}_{2} 6.6 \mathrm{kPa}, \mathrm{PCO}_{2}$ $7.1 \mathrm{kPa}$. Plasma renin while recumbent was just below the lower end of the normal range $(1.15 \mathrm{pmol} / \mathrm{h} / \mathrm{ml}$; normal range 1.2 to 2.4 ) and 11-hydroxycorticosteroids were normal. A 24-hour urinary collection started 48 hours after admission showed a potassium level of $3 \mathrm{mmol} / 1$ (normal $13 \mathrm{mmol} / 24$ hours).

$\mathrm{He}$ admitted to taking increasing quantities of kaolin and morphine mixture over the past 18 months. Initially this was for diarrhoea after drinking alcohol but subsequently he found that diarrhoea recurred when he decreased the kaolin and morphine. At the time of admission he was consuming seven bottles $(1400 \mathrm{ml})$ of kaolin and morphine daily. His wife purchased this without prescription from several chemists. After admission and discontinuation of kaolin and morphine he had a mixture of watery stools once or twice a day and hard chalky motions less often.

$\mathrm{He}$ was treated with intravenous potassium replacement, $20 \mathrm{mmol} /$ hour and after $960 \mathrm{mmol}$ over 48 hours his serum potassium had reached $3.0 \mathrm{mmol} / \mathrm{l}$. This was followed by oral potassium replacement. His power improved to normal and the ventricular ectopics stopped. Diarrhoea was initially controlled by codeine phosphate but this was discontinued after 2 weeks and bowel habit returned to normal. Three months later the serum potassium remained normal without any potassium supplements.

\section{Discussion}

Kaolin and morphine mixture (BPC) contains light kaolin $(200 \mathrm{~g} / \mathrm{l})$, sodium bicarbonate $(50 \mathrm{~g} / 1)$, chloroform and morphine tincture $(40 \mathrm{mmol} / \mathrm{l})$ together with several other constituents. Chloroform and morphine tincture is a complex mixture of anhydrous morphine $(70 \mathrm{~g} / 40 \mathrm{ml})$, chloroform and 
liquid liquorice extract. There is $45 \mathrm{~g}$ of liquorice extract per litre of kaolin and morphine; the precise amount of glycyrrhizinic acid is not controlled.

Large amounts of sodium bicarbonate alone do not usually have significant effects on serum potassium except in children or in the presence of impaired renal function. ${ }^{1}$ Liquorice has a mineralocorticoid action through its glycyrrhizinic acid content and the development of hypokalaemia may impair renal bicarbonate handling. ${ }^{2}$ It is likely that the profound hypokalaemia in the case described was produced by the combination of the liquorice extract and the bicarbonate in large amounts. Similar problems have been seen with the ingestion of liquorice alone and there appear to be considerable individual differences in the sensitivity to liquorice. ${ }^{3}$ Certainly the amounts ingested by the patient described are quite compatible with the findings. The low urinary potassium is likely to be related to the low serum level and the loss of mineralocorticoid action from the kaolin and morphine discontinued over 48 hours earlier. The effects of experimentally administered liquorice on potassium excretion would be expected to be lost in 48 hours. $^{3}$ The diarrhoea he complained of was thought to be largely spurious diarrhoea since a plain abdominal radiograph showed the colon to be full of chalky

\section{References}

1. Kirsner, J.B. \& Palmer, W.L. Studies on the effect of massive quantities of sodium bicarbonate on the acid-base equilibrium and renal function; Report of a case with remarkable tolerance. Ann Intern Med 1943, 18: 100-104.

2. Battle, D.C. \& Kurtzman, N.A. Acid-base physiology and pathophysiology. Contemp Nephrol 1985, 3: 201.

3. Cumming, A.M.M., Boddy, K., Brown, J.J. et al. Severe masses. However, it is possible that previous episodes of diarrhoea may have contributed to the potassium loss.

Hypercapnia is an unusual complication of profound metabolic alkalosis ${ }^{4}$ but respiratory centre $\stackrel{5}{9}$ depression and respiratory muscle weakness may have 0 been additional factors in its development in this patient.

Barragry \& Morris ${ }^{5}$ reported a fatal case of depen- $\mathbb{\Phi}$ dence on kaolin and morphine mixture. A 24 year old woman took in excess of $600 \mathrm{ml}$ daily and developed a serum potassium level of $1.6 \mathrm{mmol} / 1$. Post mortem $\vec{\circ}$ showed extensive myocardial necrosis compatible with prolonged hypokalaemia.

The patient described here developed considerable $\frac{}{\circ}$ potassium depletion by taking great quantities of 3 kaolin and morphine, up to $1400 \mathrm{ml}$ each day. This case illustrates the importance of a complete drug history including 'over the counter' preparations. $\nexists$ With potassium replacement and explanation the ir problems resolved. We believe that it is not widely $\stackrel{\infty}{\bullet}$ known that the standard kaolin and morphine mixture 을 contains sodium bicarbonate and liquorice extract and that excessive use can lead to profound hypokalaemia. $\subseteq$ In sensitive patients hypokalaemia might develop with a much smaller intake.

hypokalaemia with paralysis induced by small doses of liquorice. Postgrad Med J 1980, 56: 526-529.

4. Webb, J. Severe hypercapnia associated with a non-respiratory alkalosis. Br J Dis Chest 1978, 72: 62-66.

5. Barragry, J.M. \& Morris, D.V. Fatal dependence on kaolin and morphine mixture. Postgrad Med J 1980, 56: 180-182. 